\title{
KONVERTER DC-DC PENURUN TEGANGAN DUA FASA
}

\author{
Achmad Mudawari, Ali Mashar, Ahmad Deni Mulyadi, Arief Sumaryanto, Djafar Sodiq \\ Jurusan Teknik Konversi Energi- Politeknik Negeri Bandung \\ Jl. Gegerkalong Hilir, Ds. Ciwaruga - Bandung 40551 \\ Mail: achmad.mudawari@polban.ac.id
}

\begin{abstract}
Abstrak
DC-DC Konverter adalah converter yang mengubah tegangan DC konstan menjadi tegangan DC keluaran variable. Pada paper ini dibahas DC-DC konverter dua fasa menggunakan teknik modulasi PWM. Sinyal pulsa kotak tersebut diperoleh dari keluaran rangkaian sinyal pembangkit segitiga yang dibandingkan dengan sinyal tegangan DC yang dapat diatur besarnya sehingga didapatkan pulsa PWM dengan metoda frekuensi konstan yang digunakan untuk mendrive dua buah MOSFET yang berfungsi sebagai saklar elektronik yang masing-masing berbeda fasa sebesar 180 derajat. Dari hasil pengujian menunjukkan bahwa konverter DC-DC dua fasa frekuensi keluaranya dua kali frekuensi switchingnya.
\end{abstract}

Kata kunci: DC-DC konverter, PWM, Mosfet, frekuensi switching

\section{Pendahuluan}

DC-DC converter atau dikenal dengan sebutan DC chopper merupakan piranti yang mengubah sumber tegangan DC konstan menjadi tegangan keluaran variable. Ada beberapa macam topologi dari DC Chopper baik sebagai buck, boost maupun buck-boost converter. Beberapa artikel telah melakukan analisis maupun simulasi untuk buck, boost converters satu fasa maupun dua fasa namun belum disertai dengan data hasil pengujian laboaratorium Artikel ini menyajikan hasil pengujian terhadap beberapa besaran keluaran dari buck converter dua fasa.

\section{Chopper dua fasa}

Gambar 1. menggambarkan skema chopper dua fasa dengan induktor ( L ) dan kapasitor (C ) sebagai tapis keluaran. Pada prinsipnya chopper dua fasa mempunyai prinsip kerja yang sama dengan chopper satu fasa, hanya saja pada chopper dua fasa mempunyai dua kondisi konduksi yang masing-masing saling tergeser sebesar 180 derajat listrik atau $\mathrm{T} / 2$.

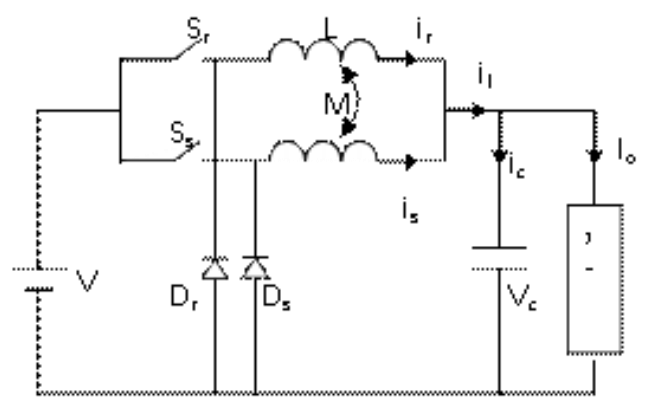

Gambar. 1. Rangkaian choper 2 fasa.

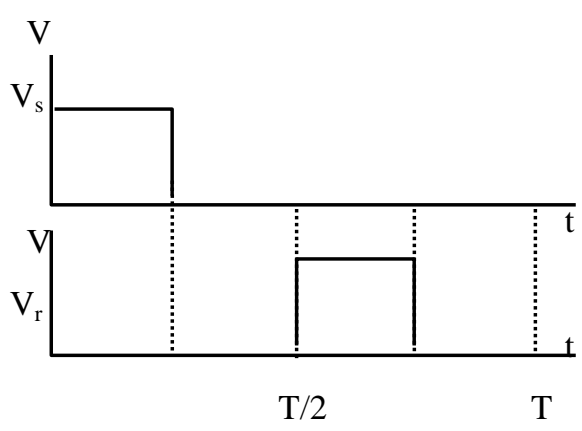

Gambar 2. Gelombang tegangan fasa untuk $0<\mathrm{D}<\mathrm{T} / 2$ 


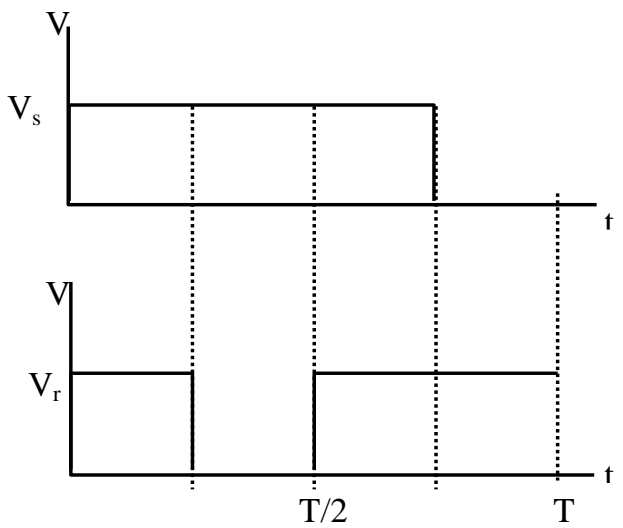

Gambar. 3. Gambar gelombang tegangan fasa untuk $\mathrm{T} / 2<\mathrm{D}<\mathrm{T}$

\section{Persamaan tegangan}

Dengan memperhatikan gambar 1, 2 dan gambar 3 maka persamaan tengangan fasa dapat dituliskan

$$
\left[\begin{array}{l}
v_{r} \\
v_{s}
\end{array}\right]=\left[\begin{array}{ll}
R & 0 \\
0 & R
\end{array}\right]\left[\begin{array}{l}
i_{r} \\
i_{s}
\end{array}\right]+p \cdot\left[\begin{array}{cc}
L & M \\
M & L
\end{array}\right]\left[\begin{array}{l}
i_{r} \\
i_{s}
\end{array}\right]+\left[\begin{array}{l}
v_{c} \\
v_{c}
\end{array}\right]
$$

\section{keterangan}

$[v]=\left[\begin{array}{ll}v_{r} & v_{s}\end{array}\right]^{t}=$ tegangan fasa

$\mathrm{R}=$ Resistansi dari induktor tapis

$[i]=\left[\begin{array}{ll}i_{r} & i_{s}\end{array}\right]^{t}=$ arus fasa

$\mathrm{p}=\mathrm{d} / \mathrm{dt}$

$\mathrm{L}=$ Induktansi diri induktor tapis

$\mathrm{M}=$ Induktansi bersama induktor tapis

$\left[v_{c}\right]=$ tegangan pada kapasitor tapis

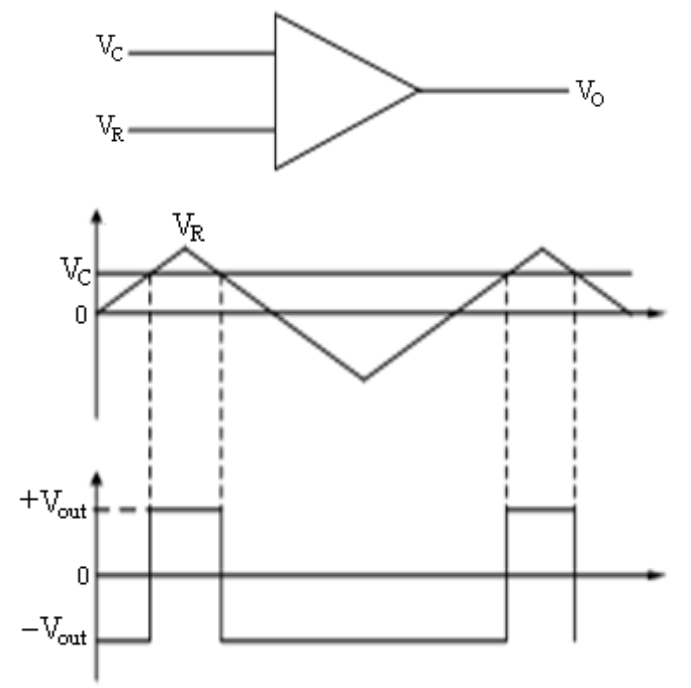

Gambar 4. Gelombang Pembentuk Modulasi Lebar Pulsa

Gelombang modulasi lebar pulsa diperoleh dengan mengumpankan tegangan referensi berbentuk segitiga $\mathrm{V}_{\mathrm{R}}$ dengan tegangan carrier $\mathrm{V}_{\mathrm{C}}$ ke sebuah komparator. Bila sinyal segitiga $\mathrm{V}_{\mathrm{R}}$ lebih besar dari $\mathrm{V}_{\mathrm{C}}$ maka keluaran komparator $\mathrm{V}_{\text {Out }}$ akan positif. Sebaliknya bila $\mathrm{V}_{\mathrm{C}}$ lebih besar daripada $\mathrm{V}_{\mathrm{R}}$ maka keluaran $\mathrm{V}_{\text {Out }}$ akan negatif.

\section{MOSFET}

MOSFET merupakan komponen elektronik yang dapat diaktifasi dengan menggunakan pulsa tegangan serta mempunyai kelebihan dalam switching speed yang tinggi.

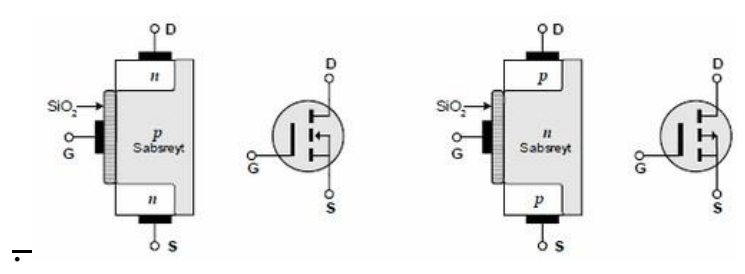

\section{Modulasi Lebar Pulsa}

Modulasi lebar pulsa merupakan cara memanipulasi lebar pulsa dalam satu perioda. Prinsip dasar modulasi lebar pulsa ditunjukkan pada gambar 4 berikut : 


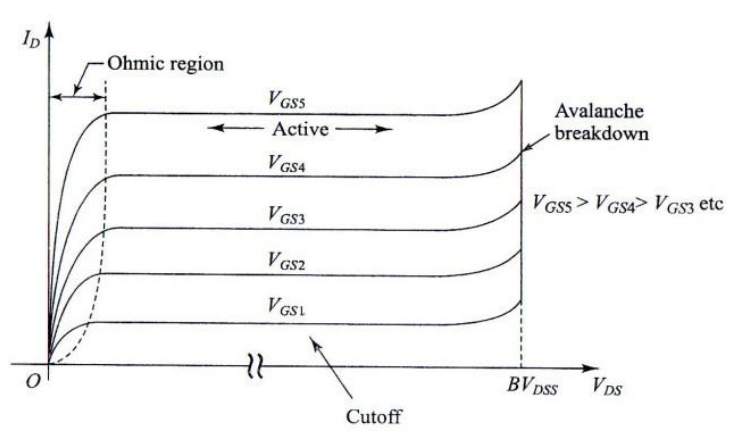

Gambar 6. Kurva Tegangan dan Arus MOSFET

\section{Rangkaian Kontrol}

Sinyal PWM untuk kontrol ON/OFF Mosfet dapat diperoleh dari gelombang segitiga yang dihasilkan IC NE566 yang dikomparasikan dengan sumber tegangan DC variable melalui komparator, untuk selanjutnya dibagi menjadi dua buah sinyal gelombang PWM yang masing-masing berbeda fasa sebesar 180 derajat.

Rangkaian control PWM terdiri dari tiga bagian utama masing-masing adalah pembangkit sinyal gelombang segitiga seperti diperlihatkan pada rangkaian berikut.

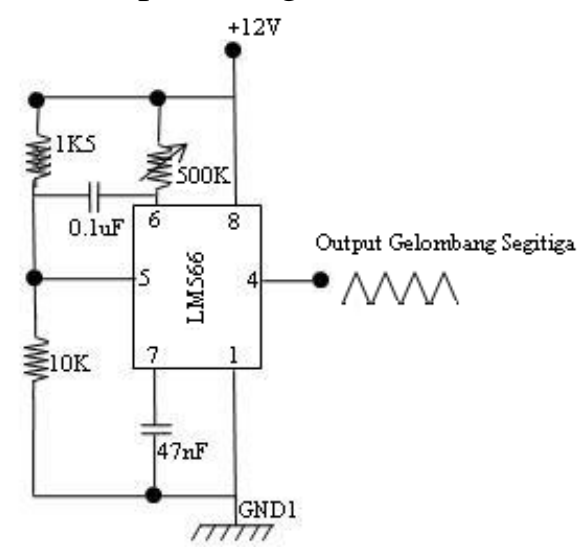

Gambar 7. Rangkaian pembangkit gelombang segitiga

hasil pengujiian gelombang segitiga adalah sbb

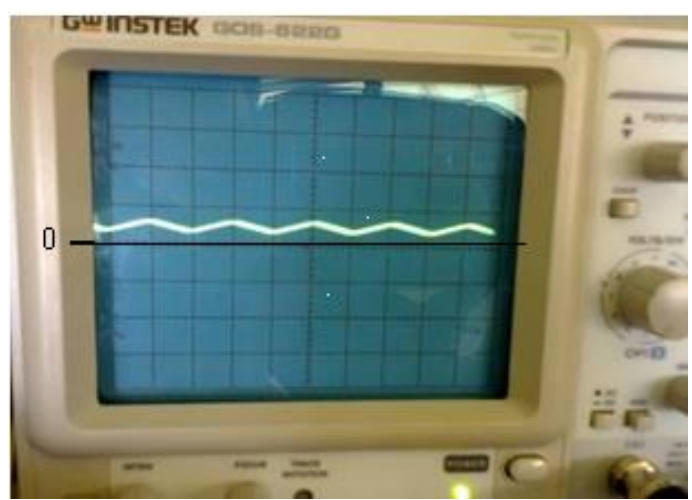

Gambar 8. Gambar pemotretan gelombang segitiga

Osiloscope : Volt/div: 5 V/div

Time/Div: $1 \mathrm{~ms} / \mathrm{div}$

Gambar 9 merupakan rangkaian penggeser fasa $180^{\circ}$ sekaligus dengan keluaran pulsa PWM yang ditampilkan pada gambar 10 .

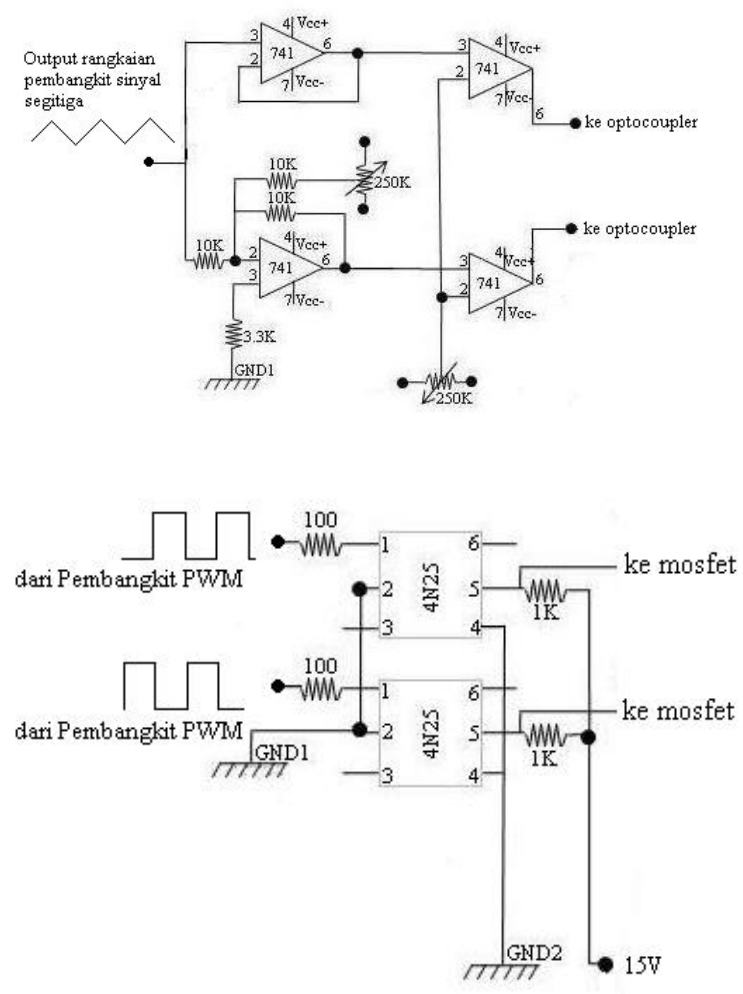

Gambar 9. Gambar rangkaian pembangkit PWM 


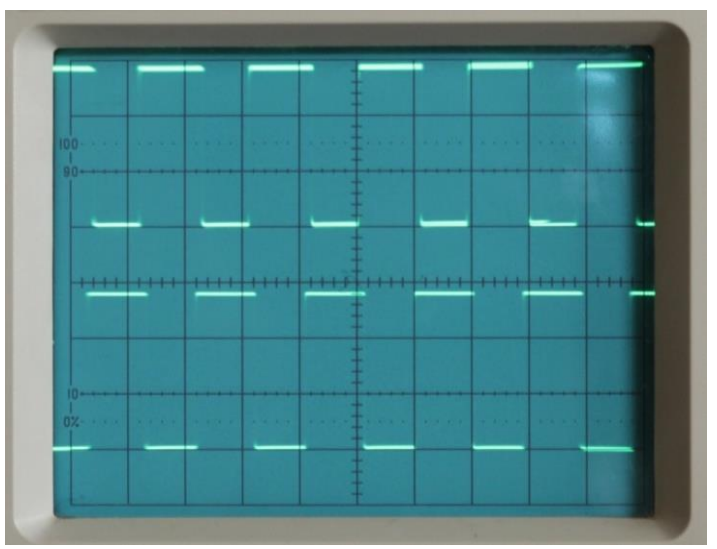

Gambar 10. Gambar pemotretan keluaran rangkaian PWM

osiloskop: Volt/div: $5 \mathrm{~V} / \mathrm{div}$

Time/Div: $1 \mathrm{~ms} / \mathrm{div}$

\section{Buck chopper 2 fasa}

Ganbar 11 berikut memperlihatkan konfigurasi buck chopper dua fasa dengan inductor filter dan beban $\mathrm{R}_{\mathrm{L}}$.

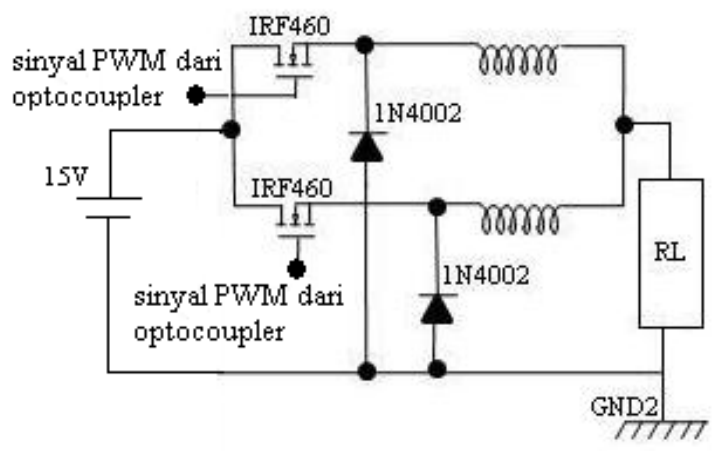

Gambar 11. Rangkaian buck converter 2 fasa

\section{Pengujian buck konverter 2 fasa}

Pengujian dilakukan dengan parameter sebagai berikut

Tegangan Masukan : $15 \mathrm{~V}$

Frekuensi switching $: 500 \mathrm{~Hz}$

Induktor $\quad: 10 \mathrm{mH}$

Beban : Lampu 12V 5W

Data hasil pengujian selengkapnya disajikan pada table 1 berikut.
Tabel 1. Data pengujian buck konverter 2 Fasa

\begin{tabular}{|c|c|c|c|c|c|}
\hline $\begin{array}{c}\text { Duty } \\
\text { Cycle }\end{array}$ & $\begin{array}{c}\text { Vin } \\
(\mathrm{V})\end{array}$ & $\begin{array}{c}\text { lin } \\
(\mathrm{mA})\end{array}$ & Vriak (V) & $\begin{array}{c}\text { lout } \\
(\mathrm{mA})\end{array}$ & $\begin{array}{c}\text { Vout } \\
(\mathrm{V})\end{array}$ \\
\hline 0 & 15 & 0 & 0 & 0 & 0 \\
\hline 0,1 & 15 & 105 & 1,04 & 100 & 2,12 \\
\hline 0,2 & 15 & 165 & 1,547 & 150 & 4,52 \\
\hline 0,3 & 15 & 210 & 1,691 & 200 & 6,44 \\
\hline 0,4 & 15 & 230 & 1,343 & 220 & 8,5 \\
\hline 0,5 & 15 & 260 & 0,55 & 257 & 9,45 \\
\hline 0,6 & 15 & 275 & 1,38 & 275 & 10,25 \\
\hline 0,7 & 15 & 290 & 1,73 & 285 & 10,66 \\
\hline 0,8 & 15 & 305 & 1,623 & 300 & 10,97 \\
\hline 0,9 & 15 & 320 & 1,044 & 312 & 11,48 \\
\hline 1 & 15 & 332 & 0,023 & 330 & 12,37 \\
\hline
\end{tabular}

\section{Analisa dan Pembahasan}

Gambar 12 memperlihatkan hasil pemotretan gelombang keluaran konverter DC-DC dua fasa. Dari gambar tersebut terlihat bahwa gelombang tegangan keluaran buck chopper dua fasaa mempunyai frekuensi sebesar $1 \mathrm{kHz}$.

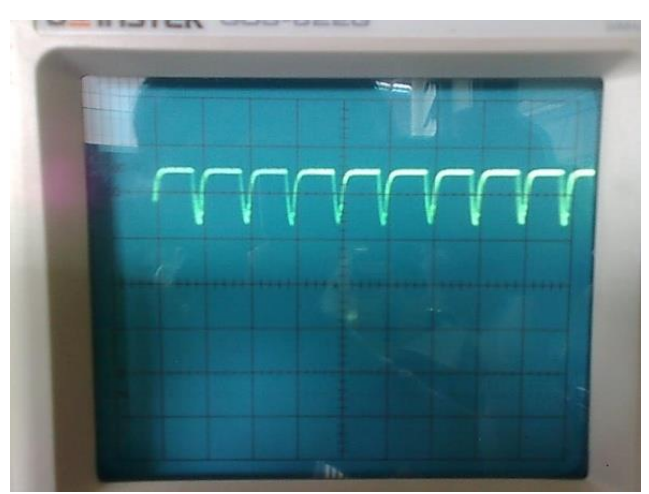

Gambar 12. Gelombang tegangan output konverter buck converter dua fasa pada duty cycle 0,9

osiloskop : Volt/div: $5 \mathrm{~V} / \mathrm{div}$

Time/Div: $1 \mathrm{~ms} / \mathrm{div}$

Frekuensi gelombang tegangan output konverter DC-DC dua fasa sebesar $1 \mathrm{kHz}$. Ini menunjukkan bahwa frekuensi gelombang tegangan output yang dihasilkan konverter DC-DC dua fasa adalah dua kali dari frekuensi switching. 


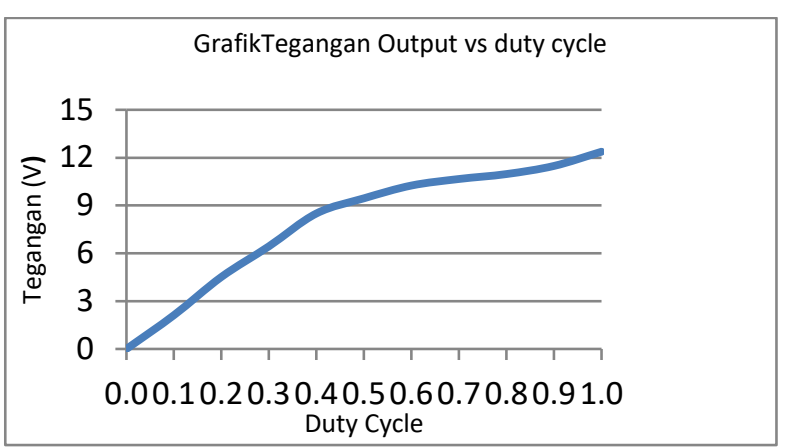

Gambar 13 Karakteristik Tegangan Output buck konverter 2 Fasa

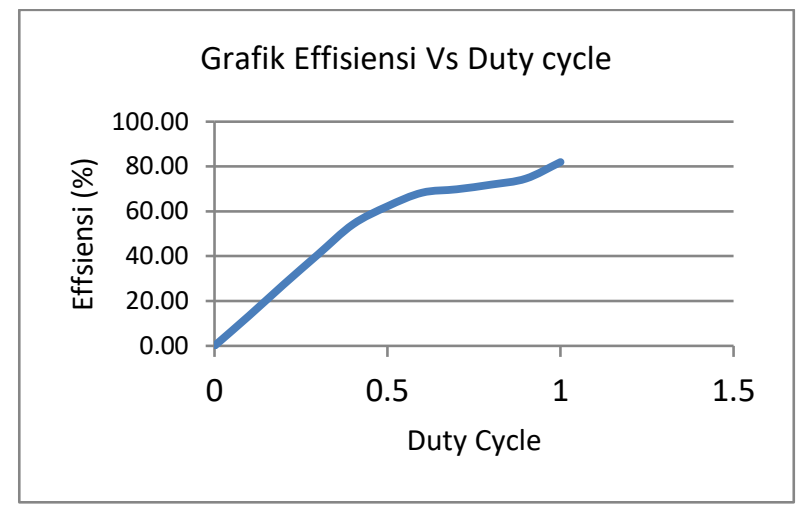

Gambar 14. Karakteristik effisiensi terhadap Duty Cycle

Gambar 13 dan gambar 14 menunjukkan masing-masing adalah grafik hubungan antara duty cycle dan tegangan keluaran serta grafik hubungan antara duty cyle dan effisiensi. Grafik tersebut menunnjukkan bahwa semakin besar duty cycle maka tegangan keluaranya juga semakin besar demikian juga dengan effisiensinya.

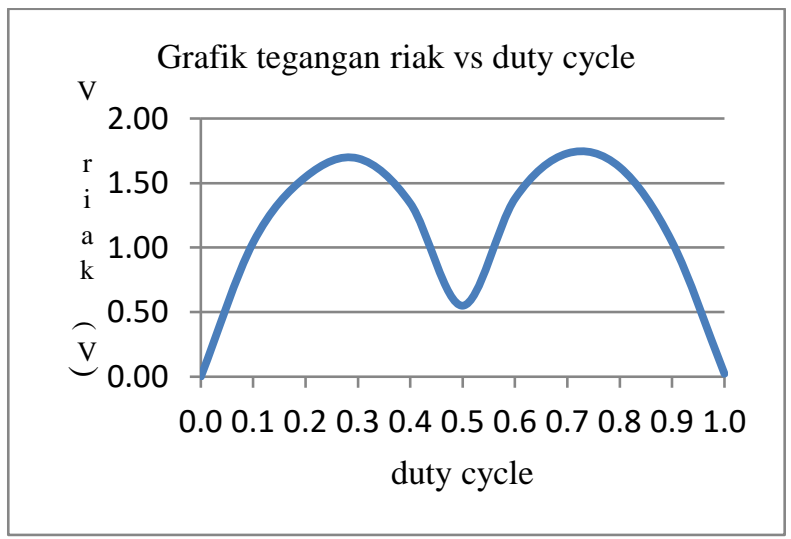

Gambar 15. Karakteristik Tegangan Riak keluaran buck konverter 2 Fasa

Gambar 15. memperlihatkan hubungan antara riak keluaran dan duty cycle. Dari gambar tersebut memperlihatkan bahwa dalam satu perioda terjadi dua gelombang riak tegangan keluaran dengan puncak masing-masing terjadi pada duty cycle 0.25 dan 0.75 dengan nilai rata-rata riak keluaran sebesar 1,061 Volt.

\section{Kesimpulan}

Dengan memperhatikan hasil pengujian konverter DC-DC penurun tegangan dua fasa dapat disimpulkan sebagai berikut:

1. Frekuensi keluaran buck chopper dua fasa adalah 2 kali frekuensi switching.

2. Dalam satu perioda terjadi dua gelombang riak tegangan keluaran yang puncaknya masing-masing terjadi pada duty cycle 0,25 dan 0,75

3. Pada pengujian dengan tegangan input 15 Volt, Induktor $10 \mathrm{mH}$ dan beban berupa lampu sebesar $5 \mathrm{~W}$, diperoleh nilai riak keluaran rata-rata sebesar 1,061 Volt

\section{DAFTAR PUSTAKA}

[1] Abdelouahab Zaatri1 and Souad Belhour2, Analysis and design of a PWM chopperon/off control via a second order filter, World Journal of Engineering 11(2) (2014) 181-186

[2] Achmad Mudawari, Pengaruh jumlah fasa terhadap Frekuensi keluaran pada Step down Chopper, Jurnal Teknik Energi, Vol1, No2, Oktober 2011, ISSN 2089 2527

[3] Achmad Mudawari, Boost Chopper dua fasa dengan Filter LC keluaran, Jurnal Teknik Energi, Vol2, No2, Oktober 2014, ISSN 2089 - 2527 
[4] Chongming (Michael) Qiao, Jason Zhang, Control of Boost type Converter in Discontinuous Conduction Mode by Controlling the Product of Inductor Voltage-Second, As presented at PESC 2005 - Recife, Brazil

[5] Jianbo Yang1, Weiping Zhang2, Faris Al-Naemi1, Xiaoping Chen2, Analysis and Modeling of Buck Converter in Discontinuous-Output-Inductor-Current Mode Operation, Energy and Power Engineering, 2013, 5, 850-856

[6] John Lee, Basic Calculation of a Buck Converter's Power Stage, AN041 (C) 2015 Richtek Technology Corporation 1

[7] N H Baharudin, T M N T Mansur, F A Hamid, R Ali, M I Misrun, Performance Analysis of DC-DC Buck Converter for Renewable Energy Application, 1st International Conference on Green and Sustainable Computing (ICoGeS) 2017,

[8] Shafinaz A. Lopa, S. Hossain, M. K. Hasan, T. K. Chakraborty. Design and Simulation of DC-DC Converters, International Research Journal of Engineering and Technology (IRJET) Volume: 03 Issue: 01 | Jan-2016 e-ISSN: $2395-0056$ 